\title{
Diaphragmatic hernia in the south-west of England
}

\author{
T. J. DAVID* and CORINNE A. ILLINGWORTH
}

From the Department of Child Health, Bristol Royal Hospital for Sick Children, Bristol, BS2 8Bf

Summary. A retrospective anatomical, family, and epidemiological study was made of 143 patients (81 female and 62 male) with diaphragmatic hernia who were born in the south-west of England between 1943 and 1974. Thirty-nine cases were stillborn.

Seventy-five per cent of patients had a left-sided diaphragmatic defect, $22 \%$ had a right-sided defect, and 3\% had a bilateral defect. Fifty per cent of the patients had other congenital malformations, most frequently of the nervous system.

No maternal age or birth order effect was noted. Cases of diaphragmatic hernia - without other malformations had in general a normal fetal growth rate. Eight per cent of the cases were illegitimate. There were two pairs of twins discordant for diaphragmatic hernia, one pair being dizygotic and the other monozygotic. In no case of diaphragmatic hernia was there a relative affected with a diaphragmatic hernia.

The most common type of diaphragmatic defect was a posterolateral hernia (92\%), followed in frequency by an eventration of the diaphragm $(5 \%)$, the least common defect being a retrocostosternal hernia $(2 \%)$. Diaphragmatic hernia appears to be aetiologically as well as anatomically heterogeneous. In this series there were two cases of trisomy 18 , one case of trisomy 21 , one case trisomic for a small part of chromosome 20, and two cases with the Pierre Robin syndrome. It seems likely that diaphragmatic hernia is a non-specific consequence of several teratological processes.

It is becoming increasingly apparent that many major congenital malformations are aetiologically heterogeneous. Individual case reports of suggested aetiological associations are vital but can only be seen in perspective in a large systematic study. Congenital diaphragmatic hernia has been described as a drug-induced entity in some reports and as a familial defect in other reports. The present survey has been performed to obtain an overall picture of the aetiology and genetics of this malformation.

Diaphragmatic hernia is a fairly common congenital malformation. The best estimate of the incidence of this defect, from the British Perinatal Mortality Survey of 1958 , is that it occurs in 0.45 per 1000 total births (Butler and Claireaux, 1962), a

Received 21 August 1975.

* Present address: Musgrove Park Branch, Taunton and Somerset Hospital, Taunton, Somerset, TA1 5DA. figure similar to the incidence in Birmingham of 0.43 per 1000 births estimated by Leck et al (1968) over the years 1950 to 1959 . Since it is known that on occasions patients with diaphragmatic hernias can survive to adult life (Kirkland, 1959; MacDougall, Abbott, and Goodhand, 1963; Ahrend and Thompson, 1971; Wolloch et al, 1974), the true incidence is probably a little greater than the figures above. There is little evidence of any geographical variation in the frequency of diaphragmatic hernia apart from a suggestion that it is particularly common in Greenland (Rønn and Andersen, 1971).

The embryology of the diaphragm seems complex and the embryogenesis of diaphragmatic hernia obscure. Accounts differ and sometimes conflict. For example, Potter (1961) said, 'Whatever conditions are responsible for such defects in the human must be active before the end of the eighth week of gestation, when final closure of the diaphragm takes 
place.' On the other hand, Baffes (1969) stated that, 'Sometime during the eighth to the tenth week of fetal life the diaphragm is formed... In a recent review, Charnock and Doershuk (1973) stated, 'Most observers agree that the embryologic formation of the diaphragm is complete by the end of the seventh week.' What is clear is that the diaphragm is constructed from several fused embryonic components, and is subject to a number of defects. These fall into three groups: (a) complete or partial absence of the diaphragm (diaphragmatic hernia without a sac); (b) failure of complete muscularization (diaphragmatic hernia with a sac, or eventration of the diaphragm); and (c) congenital enlargement of the oesophageal hiatus (hiatus hernia-not included in this study).

Diaphragmatic hernia is frequently found in association with malformations of the central nervous system (Butler and Claireaux, 1962), in particular anencephaly and iniencephaly. Indeed, Willis (1962) stated that 'one of the most constant visceral malformations accompanying iniencephaly is diaphragmatic hernia'. Some degree of pulmonary hypoplasia appears to be an almost inevitable accompaniment of cases of diaphragmatic hernia presenting in the newborn period. Malformations of the cardiovascular, genitourinary, gastrointestinal systems can be associated with diaphragmatic hernia. Diaphragmatic hernia has been reported in association with the Goldenhar syndrome (Greenwood et al, 1974), in a syndrome of defects of the anterior abdominal wall, sternum, pericardium, and heart (Toyama, 1972; Haller, 1972; Symbas and Ware, 1973), in a patient with exceptionally bizarre malformations of the genitalia and lower limbs (Schwartz, Cohn, and Haller, 1974), and as a rare complication of the asplenia syndrome (Putschar and Manion, 1956). Both diaphragmatic hernia and eventration of the diaphragm appear to be associated with the exomphalos-macroglossiagigantism syndrome (Cohen, 1969, 1971; Thorburn et al, 1970). Hypoplasia of the diaphragm, giving the radiological appearance of eventration, has been described in congenital myotonic dystrophy by Harper (1975), and eventration of the diaphragm has been recorded in an infant with probable rubella embryopathy (Briggs, Reilly, and Loewig, 1973). Diaphragmatic hernia has been reported in a case of Turner's syndrome (Bonham Carter, Waterston, and Aberdeen, 1962) and, as will be discussed later, can be associated with trisomy 18 and trisomy 21 .

Diaphragmatic hernia is generally regarded as being a non-genetic entity. However, familial cases have been reported several times. Cases have been reported in sibs by Mäkelä (1916), Mertins (1952),
Philipp and Skelton (1952), Butler and Claireaux (1962), Powell and Johnstone (1962), Welch and Cooke (1962), Passarge, Halsey, and German (1968), ten Kate and Anders (1970), Jensen and Altrogge (1971), Feingold (1971), and Daentl and Passarge (1972). Daentl and Passarge concluded that two or more sibs had been affected in nine unrelated families (they did not include all the above reports), and found probable consanguinity in one. They suggested tentatively that one should consider 'up to $25 \%$ risk of recurrence to parents who have had one child with unilateral agenesis of the diaphragm' (our italics). It has been postulated by Passarge et al (1968) that 'agenesis' of the diaphragm may constitute a distinct entity, an autosomal recessively inherited character, aetiologically different from other diaphragmatic defects. The problem with this is that in fact the diaphragm was not completely absent in many of these cases. For example, both cases of Passarge et al had an anterior rim of diaphragm present, and in one of the cases of Daentl and Passarge there was only absence of 'at least the posterior half of the diaphragm' while in the other case a posterior rim was present. Furthermore, in the family reported by Mertins (1952), in which sibs were affected, the mother had a high and flaccid diaphragm, possibly suggesting dominant inheritance. Two brothers and their maternal uncle have been reported with a congenital anterior diaphragmatic hernia (Lilly, Paul, and Rosser, 1974). Diaphragmatic hernia has been reported in distant cousins by Turpin et al (1959). A cervical hernia of the lung in the daughter of a woman with a retrocostosternal hernia was reported by Catalona, Crowder, and Chretien (1972), and the authors suggested that there might be an hereditary deficiency of the cervical mesenchyme.

Non-genetic factors have also been incriminated in the aetiology of diaphragmatic hernia. Phenmetrazine was taken by the mother of the two affected infants reported by Powell and Johnstone (1962), and a similar case was reported by Lenz (1962). Quinine has been mentioned as a possible cause of diaphragmatic hernia (Zolcinski, Heimrath, and Ujec, 1965; Kup, 1967), as has thalidomide (Hobolth, 1962). The mother of the two sibs reported by Passarge et al (1968) was taking thyroid extract and diuretics during both pregnancies.

Diaphragmatic hernia has been reported in a variety of animals including dogs (Feldman, Bree, and Cohen, 1968; Claveau, Chalifoux, and Bonneau, 1973; Zannetti and Piccinini, 1974), cats (Wilson, Newton, and Burt, 1971 ; Atkins, 1973), pigs (Griffin, 1965; Selby, Hopps, and Edmonds, 1971), monkeys (Wilson and Gavan, 1967), lambs (Dennis 
and Nairn, 1965), oxen (Done and Drew, 1972) and a calf (Lewis, 1974), horses (Priester, Glass, and Waggoner, 1970), and Siberian tigers (Brodey and Ratcliffe, 1956). In several of these reports the defect occurred in littermates, and the genetic aspects have received special attention from Fox and Crary (1973) who studied hereditary diaphragmatic hernia in the rabbit. They observed 55 cases of left diaphragmatic hernia in three related strains of rabbits under normal colony conditions. They noted an increased incidence of ventricular septal defects, and they suggested that diaphragmatic hernia was inherited as an autosomal recessive. Andersen (1949) found, in a certain stock of rats in which diaphragmatic hernia occurred spontaneously with a frequency of $0.9 \%$, that the defect increased to $18.9 \%$ by feeding a vitamin $\mathrm{A}$ deficient diet. Diaphragmatic hernia has also been produced by maternal vitamin A deficiency in various strains of rats in which the defect did not occur spontaneously (Warkany and Roth, 1948). The effect of supplementing the deficient diet with vitamin $A$ on various days of gestation was studied by Wilson, Roth, and Warkany (1953). Typically the defect in the offspring of vitamin A deficient rats was in the right dorsolateral portion of the diaphragm. Occasionally the left side as well as the right side was affected, but only rarely was the left side alone defective. A progressive reduction in the incidence of diaphragmatic hernia was achieved by the administration of single doses of vitamin $\mathrm{A}$ at progressively earlier stages of gestation. However, those animals which did develop a diaphragmatic hernia after being given vitamin A were more affected on the left side. No explanation for this shift in sidedness was given. Vitamin A deficiency has also been shown to cause left-sided diaphragmatic hernia in swine, and in some cases these defects were multiple small ones dispersed in the diaphragm (Palludan, 1966). It is worth noting that the first records of diaphragmatic hernia in animals appear to have been made in Babylonian times, some 4000 years ago (Warkany, 1971).

\section{Subjects and methods}

Cases included in this study were infants or children who had either a diaphragmatic hernia or an eventration of the diaphragm. Cases of hiatus hernia were not studied, and no attempt was made to trace adult cases.

The cases were traced in the following ways: (a) through the diagnostic index of the medical records department at the Bristol Royal Hospital for Sick Children; (b) through diagnostic indices compiled by $\mathrm{Dr} \mathrm{N}$. J. W. Royston and Dr B. W. Webb, consultant paediatricians at Taunton, and Dr F. S. W. Brimblecombe, consultant paediatrician at Exeter; (c) through the necropsy diag- nostic index compiled by Dr N. J. Brown, consultant pathologist at Southmead Hospital, Bristol; (d) by hand searching of every necropsy report at the Royal Devon and Exeter Hospital (Wonford), Exeter (by courtesy of Dr R. A. Caldwell); (e) by a search of books recording all admissions to the special care baby units of the Bristol Royal Hospital for Sick Children, the Royal Devon and Exeter Hospital (Heavitree), Exeter, and the Musgrove Park branch of the Taunton and Somerset Hospital, Taunton; (f) through a list of cases kept by Mr J. L. Griffith, consultant thoracic surgeon at Hawkmoor Hospital, Bovey Tracey.

The hospital records of every liveborn case were examined, and whenever possible antenatal details were obtained from hospital antenatal records and from the general practitioner. Though the earliest case was born in 1943, before National Health Service records had been started, it was nevertheless possible to obtain complete antenatal data in $90 \%$ of the cases.

\section{Results}

One hundred and forty three cases, born in the south-west of England between 1943 and 1974, were studied. Half the cases were born before 1966. The total of 143 cases included 62 males and 81 females, a sex ratio of 0.77 . Thirty-nine cases $(27 \%)$ were stillborn. Necropsy had been performed in all cases which had died or were stillborn. Twenty-nine patients $(20 \%)$ were alive at the time of study, and all but one had been operated upon.

It is thought that nearly complete ascertainment was achieved for all cases of diaphragmatic hernia born in Bristol between 1966 and 1974, and the incidence was estimated to be 0.33 per 1000 births. This figure includes cases with eventration of the diaphragm, the figure of Butler and Claireaux (1962) excluding these cases.

\section{Anatomical study}

Type and side of diaphragmatic defect. In 107 patients $(74.8 \%)$ the defect was on the left, in $31(21.7 \%)$ it was on the right, and in $5(3.5 \%)$ it was bilateral.

One hundred and thirty-two patients $(92.3 \%)$ had a posterolateral hernia (106 left-sided, 23 rightsided, 3 bilateral). Seven patients $(4.9 \%$ ) had an eventration ( 1 left-sided, 5 right-sided, 1 bilateral). Three patients $(2.1 \%)$ had a retrocostosternal hernia, all these defects being on the right. One patient had complete absence of the left hemidiaphragm and an eventration of the right hemidiaphragm. No attempt was made to distinguish between the 'pleuroperitoneal type' of posterolateral hernia and the posterolateral hernia due to 'congenital partial absence of the diaphragm' of Bonham Carter et al's (1962) classification. 
TABLE I

OTHER MALFORMATIONS BY SYSTEM

\begin{tabular}{l|c|c}
\hline \multicolumn{1}{c|}{ System } & Total & $\%$ \\
\hline Nervous & 40 & 28.0 \\
Gastrointestinal & 28 & 19.6 \\
Genitourinary & 21 & 14.7 \\
Cardiovascular & 19 & 13.3 \\
Skeletal & 17 & 11.9 \\
Others & 19 & 13.3 \\
\hline
\end{tabular}

TABLE II

OTHER MALFORMATIONS IN 143 CASES OF DIAPHRAGMATIC HERNIA

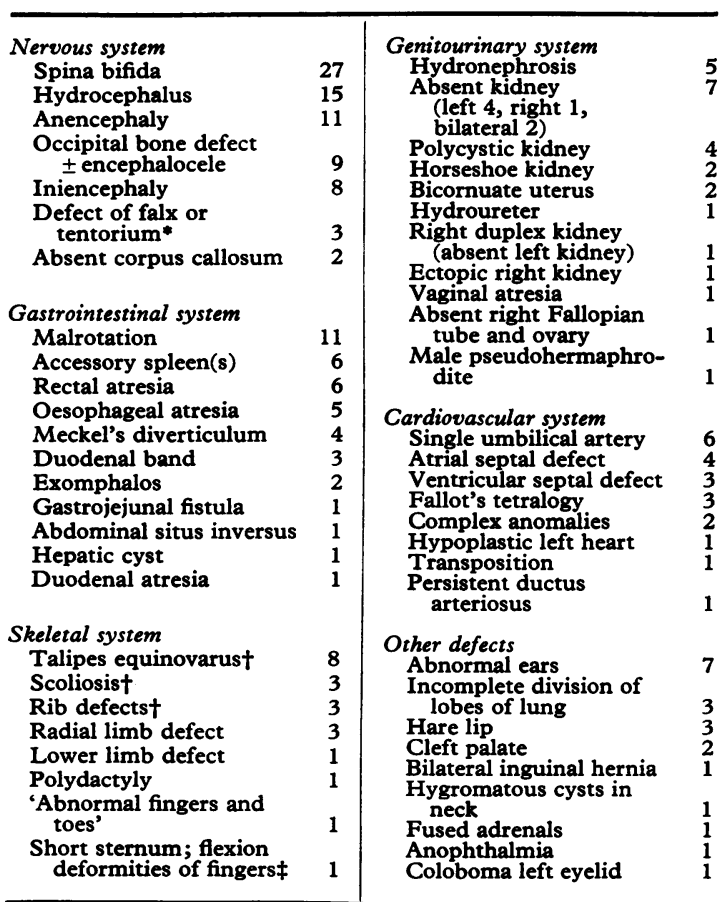

* Not due to birth injury.

$\dagger$ Not including those with neural tube defects.

$\$$ Patient had trisomy 18 .
Other malformations. Seventy-one cases $(49.7 \%)$ had no other malformations. The frequency of other malformations by system is shown in Table $I$. The malformations and their exact numbers are listed in order of frequency by systems in Table II. The frequency of other malformations appeared to be unaffected by the side of the hernia. However, stillborn cases were more likely to have other malformations than liveborn cases; of the liveborn cases those who died were more likely to have other malformations than the survivors (Table III).

Two patients had trisomy 18, and one patient had trisomy 21. One patient was trisomic for a small part of the short arm of chromosome 20, the mother and other family members being balanced translocation carriers (by courtesy of Dr A. McDermott, Cytogenetics Department, Southmead Hospital). Two patients had the Pierre Robin syndrome.

Fetal growth. Birthweight and gestation were known in 139 out of 143 cases. The fetal growth rate was assessed using the centile charts of Milner and Richards (1974) for singletons and the charts of Naeye et al (1966) for twins. The results are shown in Table IV. If one takes infants below the 2.3rd centile as showing unequivocal fetal growth retardation, then at least 24 cases had fetal growth retardation. However, it seemed likely that the cases with low fetal growth rates were those with other malformations (especially nervous system defects) so that the fetal growth rate of the cases without other malformations is also shown in Table IV.

TABLE III

SURVIVAL IN DIAPHRAGMATIC HERNIA ACCORDING TO PRESENCE OF OTHER MALFORMATIONS

\begin{tabular}{l|c|c|c}
\hline & Stillborn & Died & Living \\
\cline { 2 - 4 } $\begin{array}{l}\text { No other malformations } \\
\text { Other malformations present }\end{array}$ & 35 & 43 & 24 \\
\hline
\end{tabular}

TABLE IV

WEIGHT FOR DATES OF 143 CASES OF DIAPHRAGMATIC HERNIA

\begin{tabular}{|c|c|c|c|c|c|c|c|c|c|}
\hline & \multicolumn{8}{|c|}{ Centile } & \multirow{2}{*}{ Total } \\
\hline & $<2.3$ & 2.3-9 & $10-24$ & $25-49$ & $50-74$ & $75-89$ & $90-97.7$ & $>97.7$ & \\
\hline All cases & $\begin{array}{c}24 \\
(17.3 \%)\end{array}$ & $\begin{array}{c}19 \\
(13.7 \%)\end{array}$ & $\begin{array}{c}23 \\
(16.5 \%)\end{array}$ & $\begin{array}{c}29 \\
(20.9 \%)\end{array}$ & $\begin{array}{c}23 \\
(16.5 \%)\end{array}$ & $\begin{array}{c}13 \\
(9.4 \%)\end{array}$ & $\begin{array}{c}7 \\
(5.0 \%)\end{array}$ & $(0.7 \%)$ & 139 \\
\hline $\begin{array}{l}\text { Cases with no other } \\
\text { malformations }\end{array}$ & $(2.9 \%)$ & $\begin{array}{c}7 \\
(10.3 \%)\end{array}$ & $\begin{array}{c}10 \\
(14.7 \%)\end{array}$ & $\begin{array}{c}15 \\
(22.1 \%)\end{array}$ & $\begin{array}{c}16 \\
(23.5 \%)\end{array}$ & $(16.2 \%)$ & $(8.8 \%)$ & $(1.5 \%)$ & 68 \\
\hline
\end{tabular}




\section{Family study}

Father's occupation and social class. The father's occupation was recorded in 103 cases (72\%). There did not appear to be an excess of any particular occupation. The social class distribution of the fathers is shown in Table V, using figures from the 1966 Census to calculate the expected figures. There was a significant difference between the observed and the expected figures.

TABLE V

FATHER'S SOCIAL CLASS

\begin{tabular}{l|c|c|c}
\hline & \multicolumn{3}{|c}{ Social Class } \\
\cline { 2 - 4 } & $1+2$ & 3 & $4+5$ \\
\hline Observed & 14 & 44 & 45 \\
\hline & 23.9 & 49.3 & 29.8 \\
\hline
\end{tabular}

$x_{(2)}^{2}=12.4 ; P<0.005$

Legitimacy. There were 12 illegitimate cases $(8.4 \%)$. In 7 of these it was the mother's first pregnancy, in 3 her second, and in 2 her third (excluding previous miscarriages and stillbirths).

Maternal age and birth order. The maternal age could not be ascertained in 13 cases (9.1\%), and the birth order was not recorded in 7 cases $(4.9 \%)$. The maternal age and birth order distributions of legitimate cases were compared with the expected numbers estimated from the distribution of legitimate births in the Registrar General's 1964 figures for England and Wales. The figures are shown in Tables VI and VII. Neither the birth order nor the maternal age distributions differed significantly from the expected figures.

Twins. There were two twins with diaphragmatic hernia. One was a second born female with a left posterolateral hernia and no other defects. Her twin brother had hypospadias. The other was illegitimate, a second born female, with a left posterolateral hernia and a bilobed right lung. Her female co-twin was normal. They were born at 31
TABLE VII

DISTRIBUTION BY NUMBER OF PREVIOUS LIVEBORN SIBS, STANDARDIZED FOR MATERNAL AGE

\begin{tabular}{l|l|l|l|l|l}
\hline \multirow{2}{*}{} & \multicolumn{4}{|c|}{ Birth Order } & \multirow{2}{*}{ Total } \\
\cline { 2 - 5 } & 0 & 1 & \multicolumn{1}{|c|}{2} & $3+$ & \\
\hline Observed & 56 & 38 & 21 & 14 & 129 \\
Expected & 45.97 & 40.05 & 21.80 & 21.18 & \\
\hline
\end{tabular}

weeks' gestation and both died of respiratory distress after a few hours. The placenta was diamniotic and monochorionic. Thus the twins were presumed to be monozygotic.

Sibs with malformations. No attempt was made to visit the families to get information about sibs. In the 127 cases where information about sibs was available (from hospital and general practitioners' records), and excluding the twins described above, there were 151 older sibs (including stillbirths) and 30 younger sibs. In no case was there a sib or any other relative known to have a diaphragmatic hernia. The other malformations found in the 181 sibs are listed in Table VIII. In one case the birth of the patient, who also had an occipital encephalocele, was preceded by the birth of two infants with spina bifida. In another case the birth of the patient, who also had anencephaly and craniorachischisis, was preceded by the birth of three anencephalics Two cases of diaphra gmatic hernia, both also with major nervous system

TABLE VIII

MALFORMATIONS IN SIBS OF CASES OF DIAPHRAGMATIC HERNIA

Anencephaly (with craniorachischisis in two)

Spina bifida alone

Talipes equinovarus

Cleft palate

Hare lip

Absent left kidney

Ventricular septal defect

TABLE VI

DISTRIBUTION BY MATERNAL AGE STANDARDIZED FOR BIRTH ORDER

\begin{tabular}{|c|c|c|c|c|c|c|}
\hline & \multicolumn{5}{|c|}{ Maternal Age (yr) } & \multirow{2}{*}{ Total } \\
\hline & $15-19$ & $20-24$ & $25-29$ & $30-34$ & $35+$ & \\
\hline Observed & 10 & 48 & 40 & 13 & 18 & 129 \\
\hline Expected & 9.62 & 41.26 & 41.22 & 22.89 & 14.01 & 187 \\
\hline
\end{tabular}


malformations, had been preceded by a neonatal death the cause of which was not recorded in the antenatal notes of the subsequent pregnancy. There were also two cases of uncomplicated left posterolateral hernias which had been preceded by a stillbirth the cause of which was not recorded in the antenantal notes of the subsequent pregnancy. These last four mentioned cases were all in the Bristol clinical area where the necropsy rate for stillbirths and neonatal deaths is very high, and it is thought highly improbable that these four previous dead babies had a diaphragmatic hernia or other major malformation.

Malformations in other relatives. One mother had three thoracic hemivertebrae, another had a duplex kidney, another had infantile pyloric stenosis, and another had a vaginal septum. One maternal aunt had a 'hole in the heart'.

\section{Epidemiological study}

It was thought that nearly complete ascertainment had been achieved for Bristol and Devon between 1966 and 1974, and these cases were, therefore, used to look for yearly and monthly fluctuations and for clustering. The date of conception was estimated for every case.

As for the yearly fluctuations no linear trend was evident. Assuming that there ought to be an equal number of cases conceived each month, no significant difference between the observed and expected figures was found for the number of cases conceived each month. No cyclic trend or seasonal effect could be seen. Time clustering was looked for, applying Knox's (1959) time interval analysis method to the estimated dates of conception. The results (Table IX) do not show any increased risk of a case occurring within four weeks of a previous case.

\section{TABLE IX}

TIME INTERVAL ANALYSIS BASED ON ESTIMATED DATES OF CONCEPTION OF 61 CASES CONCEIVED BETWEEN 1 JANUARY 1966 AND 31 DECEMBER 1973 AND BORN IN BRISTOL OR DEVON, BY METHOD OF KNOX (1959)

\begin{tabular}{l|c|c|c|c|c}
\hline & \multicolumn{5}{|c}{ No. of Days after Index Case } \\
\cline { 2 - 6 } & $0-6$ & $7-13$ & $14-20$ & $21-27$ & $28-41$ \\
\hline Interval & 7 & 7 & 7 & 7 & 14 \\
Observed & 7 & 4 & 10 & 9 & 16 \\
Expected & 8.77 & 8.77 & 8.77 & 8.77 & 17.54 \\
Excess & -1.77 & -4.77 & 1.23 & 0.23 & 1.54 \\
\hline
\end{tabular}

\section{Complications of pregnancy}

Hydramnios was recorded in 46 out of 143 cases $(32.2 \%)$. Seventeen of those with hydramnios had nervous system malformations, well known to be associated with hydramnios. Excluding all cases with nervous system malformations, as well as those with oesophageal or duodenal atresia, hydramnios was present in 27 out of 98 cases $(27.6 \%)$. Preeclampsia was recorded in 29 cases $(20.3 \%)$. A threatened abortion in the first trimester was recorded in eight cases. Six mothers had anaemia (haemoglobin less than $60 \%$ ), three had overt diabetes mellitus, four had urinary infections, and three had asthma.

\section{Discussion}

It is difficult to compare this study with previous series, all of which had smaller numbers and only one of which included stillbirths and early neonatal deaths (Butler and Claireaux, 1962).

Sex, side, and type of defect. Diaphragmatic hernia was more common in females than males, with a sex ratio of 0.77 . This is in contrast with the figures from much smaller previous series of 1.88 , $1.62,1.1,0.67$, and 0.5 of Johnson, Deaner, and Koop (1967), Bonham Carter et al (1962), Lester, Vesterdal, and Winkel Smith (1959), Butler and Claireaux (1962), and Sokolowska-Pituchowa and Kusionowicz (1962), respectively. Why these figures should be so very different is far from clear.

The present series contains a lower proportion of left-sided defects $(75 \%)$ than any previous seriesfigures which range from $78 \%$ (Baffes, 1969) to $92 \%$ (Butler and Claireaux, 1962). Nevertheless, the predominance of left-sided defects remains, and may be related to the fact that during development the right duct of Cuvier is much larger than the left one, closure of the duct usually occurring first on the right side (Hamilton, Boyd, and Mossman, 1972).

By far the commonest type of defect in this series was the posterolateral defect, found in 132 out of 143 cases $(92 \%)$. Whether eventration of the diaphragm should be included in a study of diaphragmatic hernia is arguable, but it is of interest that in one of the eight patients with an eventration in this series there was an eventration of the right hemidiaphragm with absence of the left hemidiaphragm. Three patients had a retrocostosternal hernia, and one of these was a girl with trisomy 21, the association having been reported before (Donovan, 1938, 1945; Spencer and Rogerson, 1951; Baran et al, 1967). No evidence was found in this study to suggest that different types of diaphragmatic defect 
had different aetiologies (though this is very likely), except for the association between trisomy 21 and retrocostosternal hernias. The association between trisomy 18 and eventration of the diaphragm (Hecht et al, 1963; Taylor, 1968; Barash, Freedman, and Opitz, 1970; Warkany, 1971) was not noted in this series. Both cases of trisomy 18 had left posterolateral hernias, in one case very large. These associations are clearly not exclusive: lateral diaphragmatic defects have been reported in trisomy 21 (Warkany, Passarge, and Smith, 1966), and posterolateral hernias have been reported in trisomy 18 (Kajii et al, 1964; Sommer and Grosfeld, 1970). There must be reservations about estimates of the size of the defect made by different pathologists and surgeons, and such estimates have been avoided in this study. The term 'agenesis' of the diaphragm, conveying as it does the idea of total agenesis, is difficult to justify because in most cases it is clear that part of the diaphragm was still present. Indeed, the evidence that the familial diaphragmatic hernias are in general larger defects than usual is far from convincing; certainly in the present study 'very large' defects were the most frequent ones. Similarly, 'aplasia' of the diaphragm is confusing and invariably inappropriate.

Associated malformations. Though potentially remediable by surgery, diaphragmatic hernia remains (and is likely to remain) a fatal lesion for a large percentage of infants with symptoms in the first few days of life, death being the result of hypoplasia of the lungs. In this study hypoplasia of the lungs has not been included as an 'associated malformation' for two reasons. One is that it is perhaps not a true malformation. The other is that it appears to be an almost inevitable complication of diaphragmatic hernia presenting at or soon after birth. Indeed, a residual defect in ventilatory function despite a satisfactory repair of the hernia has been shown in children who survived operation in infancy (Chatrath, El Shafie, and Jones, 1971). This pulmonary hypoplasia has attracted a good deal of attention, and is widely held to be the result of compression of the lung by viscera in the chest (Boyden, 1972; Reale and Esterly, 1973). Hypoplastic lungs have been found in lambs with surgically produced congenital diaphragmatic hernia (de Lorimier, Tierney, and Parker, 1967). Though simple compression is accepted as the cause of pulmonary hypoplasia, the mechanism may in fact be a little different. Recently, it has been observed that the human fetus makes irregular breathing movements from late in the first trimester, and in the last trimester these movements become regular as after birth (Boddy and Dawes, 1975). It seems reasonable to assume that these fetal breathing movements, with inflow and outflow of amniotic fluid, are necessary for pulmonary development. If this is so, then the pulmonary hypoplasia common to infants with diaphragmatic hernia, renal agenesis, and anencephaly (Reale and Esterly, 1973) could share a final pathway-impaired fetal breathing. In diaphragmatic hernia compression of the ipsilateral lung would impair expansion, and the other lung would be similarly affected (as it often is) if there is sufficient mediastinal shift. In renal agenesis the oligohydramnios might reduce the total inflow and outflow of amniotic fluid as well as making breathing movements more restricted, and in anencephaly presumably fetal breathing movements could be reduced in much the same way as swallowing of the amniotic fluid is reduced.

Excluding pulmonary hypoplasia, which was not included as a malformation in this study, just over $50 \%$ of cases had other malformations, similar to the figure of $57 \%$ of Leck et al (1968). Abnormalities of the nervous system were the most frequent, as in Butler and Claireaux's (1962) series, in particular anencephaly or iniencephaly (both usually combined with spina bifida). The reverse association also seems to be fairly common. From the Second Report (Butler and Alberman, 1969) of the British Perinatal Mortality Survey, it appears that diaphragmatic hernia was present in $11 \%$ of anencephalics with spina bifida, though only in 3\% of anencephalics without spina bifida. In a study of anencephaly in Bristol, the corresponding figures were $7 \%$ and $3 \%$, respectively (David and Nixon, 1976). In the gastrointestinal system the most frequent malformation was malrotation, noted in $8 \%$ of cases. 'Malfixation of the mesentery' was noted in $20 \%$ of cases by Butler and Claireaux (1962), and this was thought to be under-reported. It was not noted specifically in the present study since cases with much gut in the chest almost certainly have a long unfixed mesentery. A single umbilical artery was the most frequently associated cardiovascular malformation, and the possible relation between it and diaphragmatic hernia was discussed by Chaurasia (1974). Two cases of diaphragmatic hernia had the Pierre Robin syndrome, an association that does not appear to have been previously reported.

Fetal growth. Seventeen per cent of cases of diaphragmatic hernia in the present series had unequivocal fetal growth retardation, but this could mainly be attributed to major nervous system malformations. When cases of diaphragmatic hernia 
without other malformations were studied separately fetal growth retardation was only present in two out of 68 cases, the distribution of fetal growth rates was not shifted to the left, and exactly the same number of cases had a fetal growth rate above the 50 th centile as below it.

Father's occupation and social class. The distribution of the father's social class differed significantly from the expected figures when classes 1 and 2 and 4 and 5 were combined. This was because of a deficit in the upper social classes and an excess in the lower social classes (not because of the presence of cases with nervous system malformations in the series). The numbers are small and this is a finding that requires confirmation, particularly as Butler and Claireaux (1962) did not find a social class effect.

Legitimacy, maternal age, and birth order. The $8 \%$ illegitimacy rate found in this series does not seem excessive. No significant maternal age or birth order effect was found, in agreement with Butler and Claireaux's (1962) findings.

Genetics and twinning. In no case in this series was there a known or suspected case of diaphragmatic hernia in a relative. Though familial cases have been reported (see above), they are clearly exceptional. Four cases of diaphragmatic hernia had one or more sibs with a neural tube defect. In two cases the infant with the hernia also had a neural tube defect; in the other two there were no other malformations. Two out of the 143 cases of diaphragmatic hernia were from twin pregnancies, one dizygotic and the other monozygotic. It should be noted that an examination of the concordance or discordance for diaphragmatic hernia in twins cannot give any guide as to the relative importance of genetic or environmental factors in the aetiology of diaphragmatic hernia in general. Diaphragmatic hernia has been reported in two of three monozygotic iniencephalic triplets by Scott and Paterson (1966).

Epidemiology. The extreme rarity of familial recurrence of diaphragmatic hernia seems to point to either non-recurrent or immunizing teratogens. With this in mind, a search for time clustering was made, with a negative result. The absence of any pronounced clustering in time and the absence of a seasonal trend probably excludes epidemic infections as a major cause of diaphragmatic hernia. However, endemic infectious diseases cannot be excluded on these grounds and would fit in with the observed though unconfirmed social class gradient. Slater, Watson, and McDonald (1964) also failed to find a seasonal trend for diaphragmatic hernia.

Complications of pregnancy. Hydramnios, known to be associated with diaphragmatic hernia, was found in $28 \%$ of cases without nervous system malformations or oesophageal or duodenal atresia. Three mothers had overt diabetes mellitus, but previous evidence linking maternal diabetes and diaphragmatic hernia is weak (Kučera, 1971). In no case was there a record of the mother having taken phenmetrazine or quinine, though this in no way excludes any form of drug ingestion.

Conclusions. Just over half of all cases of diaphragmatic hernia have other malformations which are often serious or fatal. There are several different patterns of associated malformations, and it is conceivable that diaphragmatic hernia is a nonspecific result of several teratological processes. This creates considerable difficulties when trying to compare the findings in this study with others, since other series may not contain the same proportions of aetiologically different subgroups. Progress in the future will depend upon the ability to recognize aetiological entities within a group of apparently similar malformations.

The authors would like to thank Mr R. H. R. Belsey, Dr F. S. W. Brimblecombe, Dr N. J. Brown, Professor N. R. Butler, Dr R. A. Caldwell, Mr J. L. Griffith, Mrs A. Hoskins, Professor R. S. Illingworth, Dr P. J. Kearney, Mrs A. F. Morris, Dr N. J. W. Royston, Dr M. Vowles, Dr M. A. Voyce, Dr B. W. Webb, and Mrs J. Williams for their help, and the Inner Wheel Club of Kingswood, Bristol, for their financial support.

\section{REFERENCES}

Ahrend, T. R. and Thompson, B. W. (1971). Hernia of the foramen of Bochdalek in the adult. American fournal of Surgery, 122, 612-615.

Andersen, D. H. (1949). Effect of diet during pregnancy upon the incidence of congenital hereditary diaphragmatic hernia in the rat. American fournal of Pathology, 25, 163-185.

Atkins, C. E. (1973). Suspect congenital peritineopericardial diaphragmatic hernia in an adult cat. Fournal of the American Veterinary Medical Association, 162, 175-176.

Baffes, T. G. (1969). Diaphragmatic hernia. In Pediatric Surgery, 2nd ed., Vol. 1, pp. 342-356. Ed. by W. T. Mustard, M. M. Ravitch, W. H. Snyder, K. J. Welch, and C. D. Benson. Year Book Medical Publishers, Chicago.

Baran, E. M., Houston, H. E., Lynn, H. B., and O'Connell, E. J. (1967). Foramen of Morgagni hernias in children. Surgery, 62, 1076-1081.

Barash, B. A., Freedman, L., and Opitz, J. M. (1970). Anatomic studies in the 18-trisomy syndrome. Birth Defects: Original Article Series, 6, No. 4, pp. 3-15. National Foundation-March of Dimes, New York.

Boddy, K. and Dawes, G. S. (1975). Fetal breathing. British Medical Bulletin, 31, 3-7.

Bonham Carter, R. E., Waterston, D. J., and Aberdeen, E. (1962). Hernia and eventration of the diaphragm in childhood. Lancet, 1 , 656-659. 
Boyden, E. A. (1972). The structure of compressed lungs in congenital diaphragmatic hernia. American fournal of Anatomy, 134, 497-507.

Briggs, V. A., Reilly, B. J., and Loewig, K. (1973). Lung hypoplasia and membranous diaphragm in the congenital rubella syndromea rare case. Fournal of the Canadian Association of Radiologists, 24, 126-127.

Brodey, R. S. and Ratcliffe, H. L. (1956). Congenital diaphragmatic hernia in the tiger-two case reports. Fournal of the American Veterinary Medical Association, 129, 100-102.

Butler, N. R. and Alberman, E. D. (1969). (Eds.) Perinatal Problems. The Second Report of the 1958 British Perinatal Mortality Survey, plate 1 facing p. 304. Churchill Livingstone, Edinburgh.

Butler, N. R. and Claireaux, A. E. (1962). Congenital diaphragmatic hernia as a cause of perinatal mortality. Lancet, 1, 659-663.

Catalona, W. J., Crowder, W. L., and Chretien, P. B. (1972). Occurrence of hernia of Morgagni with filial cervical lung hernia: a hereditary defect of the cervical mesenchyme? Chest, 62, 340342.

Charnock, E. L. and Doershuk, C. F. (1973). Developmental aspects of the human lung. Pediatric Clinics of North America, 20, 275-292.

Chatrath, R. R., El Shafie, M., and Jones, R. S. (1971). Fate of hypoplastic lungs after repair of congenital diaphragmatic hernia. Archives of Disease in Childhood, 46, 633-635.

Chaurasia, B. D. (1974). Single umbilical artery with caudal defects in human fetuses. Teratology, 9, 287-298.

Claveau, R., Chalifoux, A., and Bonneau, N. H. (1973). Une hernie diaphragmatique avec effusion pleurale chez un chien. Canadian Veterinary fournal, 14, 277-279.

Cohen, M. M. (1969). Comment on the macroglossia-omphalocele syndrome. Birth Defects. Original Article Series, 5, pt. 2, p. 197. National Foundation-March of Dimes, New York.

Cohen, M. M. (1971). Macroglossia, omphalocele, visceromegaly, cytomegaly of the adrenal cortex and neonatal hypoglycemia. Birth Defects: Original Article Series, 7, pt. 7, pp. 226-232. National Foundation-March of Dimes, New York.

Daentl, D. L. and Passarge, E. (1972). Familial agenesis of the diaphragm. Birth Defects: Original Article Series, 8, pt. 2, pp. 24-26. National Foundation-March of Dimes, New York.

David, T. J. and Nixon, A. (1976). Congenital malformations associated with anencephaly and iniencephaly. Fournal of Medical Genetics, 13, 263-265.

de Lorimier, A. A., Tierney, D. F., and Parker, H. R. (1967). Hypoplastic lungs in fetal lambs with surgically produced congenital diaphragmatic hernia. Surgery, 62, 12-17.

Dennis, S. M. and Nairn, M. E. (1965). Two cases of congenital diaphragmatic hernia in Australian Merino lambs. Veterinary Record, 77, 754.

Done, S. H. and Drew, R. A. (1972). Aperture in the diaphragm with protrusion of abnormal liver tissue. A report of three cases in the ox. British Veterinary fournal, 128, 553-559.

Donovan, E. J. (1938). Congenital diaphragmatic hernia. Annals of Surgery, 108, 374-388.

Donovan, E. J. (1945). Congenital diaphragmatic hernia. Annals of Surgery, 122, 569-581.

Feingold, M. (1971). Aplasia of the diaphragm. Pediatrics, 47, 601-603.

Feldman, D. B., Bree, M. M., and Cohen, B. J. (1968). Congenital diaphragmatic hernia in neonatal dogs. Fournal of the American Veterinary Medical Association, 153, 942-944.

Fox, R. R. and Crary, D. D. (1973). Hereditary diaphragmatic hernia in the rabbit. Fournal of Heredity, 64, 333-336.

Greenwood, R. D., Rosenthal, A., Sommer, A., Wolff, G., and Craenen, J. (1974). Cardiovascular malformations in oculoauriculovertebral dysplasia (Goldenhar syndrome). Fournal of Pediatrics, 85, 816-818.

Griffin, R. M. (1965). Congenital diaphragmatic hernia in the piglet. Veterinary Record, 77, 492-494.

Haller, J. A. (1972). A syndrome of combined congenital defects of supraumbilical abdominal wall, lower sternum, diaphragm and heart. Birth Defects: Original Article Series, 8, pt. 5, pp. 140-142.

Hamilton, W. J., Boyd, J. D., and Mossman, H. W. (1972). Human Embryology, 2nd ed., pp. 365-367. Ed. by W. J. Hamilton and H. W. Mossman. Heffer, Cambridge.

Harper, P. S. (1975). Congenital myotonic dystrophy in Britain. I. Clinical aspects. Archives of Disease in Childhood, 50, 505-513. Hecht, F., Bryant, J. S., Motulsky, A. G., and Giblett, E. R. (1963).
The no. 17-18 (E) trisomy syndrome. Studies on cytogenetics, dermatoglyphics, paternal age, and linkage. Fournal of Pediatrics, 63, 605-621.

Hobolth, N. (1962). Drugs and congenital abnormalities. Letter to the editor. Lancet, 2, 1333-1334.

Jensen, M. and Altrogge, H. C. (1971). Familiäre Zwerchfellagenesie. Monatsschrift fur Kinderheilkunde, 119, 609-610.

Johnson, D. G., Deaner, R. M., and Koop, C. E. (1967). Diaphragmatic hernia in infancy: factors affecting the mortality rate. Surgery, 62, 1082-1091.

Kajii, T., Oikawa, K., Itakura, K., and Ohsawa, T. (1964). A probable 17-18 trisomy syndrome with phocomelia, exomphalos, and agenesis of hemidiaphragm. Archives of Disease in Childhood, 39, 519-522.

Kirkland, J. A. (1959). Congenital posterolateral diaphragmatic hernia in the adult. British fournal of Surgery, 47, 16-22.

Knox, G. (1959). Secular pattern of congenital oesophageal atresia. British fournal of Preventive and Social Medicine, 13, 222-226.

Kučera, J. (1971). Rate and type of congenital anomalies among offspring of diabetic women. Fournal of Reproductive Medicire, 7, 73-82.

Kup, J. (1967). Zwerchfelldefekt nach Abtreibungsversuch mit Chinin. Münchener medizinische Wochenschrift, 27, 2582-2583.

Leck, I., Record, R. G., McKeown, T., and Edwards, J. H. (1968). The incidence of malformations in Birmingham, England, 19501959. Teratology, 1, 263-280.

Lenz, W. (1962). Drugs and congenital abnormalities (letter). Lancet, 2, 1332-1333.

Lester, J., Vesterdal, J., and Winkel Smith, C. C. (1959). Twentyone cases of anterior and posterior diaphragmatic hernias in children. Acta paediatrica Scandinavica, 48, 175-183.

Lewis, A. M. (1974). Congenital diaphragmatic hernia in the calf. Veterinary Record, 94, 102.

Lilly, J. R., Paul, M., and Rosser, S. B. (1974). Cited by V. A. McKusick (1975) in Mendelian Inheritance in Man, 4th ed. Johns Hopkins University Press, Baltimore.

MacDougall, J. T., Abbott, A. C., and Goodhand, T. K. (1963). Herniation through congenital diaphragmatic defects in adults. Canadian fournal of Surgery, 6, 301-316.

Mäkelä, V. (1916). Hernia diaphragmatica congenita spuria. Finska Läkaresällskapets Handlingar, 58, 1107-1127.

Mertins, H. (1952). Uber eine familiare Zwerchfellmissbildung. Zentralblatt für Gynäkologie, 74, 951-955.

Milner, R. D. G. and Richards, B. (1974). An analysis of birth weight by gestational age of infants born in England and W'ales, 1967 to 1971. Fournal of Obstetrics and Gynaecology of the British Commonwealth, 81, 956-967.

Naeye, R. L., Benirschke, K., Hagstrom, J. W. C., and Marcus, C. C. (1966). Intrauterine growth of twins as estimated from liveborn birth-weight data. Pediatrics, 37, 409-416.

Palludan, B. (1966). A-Avitaminosis in Swine. A Study on the Importance of Vitamin A for Reproduction, pp. 118-242. Munksgaard, Copenhagen

Passarge, E., Halsey, H., and German, J. (1968). Unilateral agenesis of the diaphragm. Humangenetik, 5, 226-230.

Phillip, E. E. and Skelton, M. O. (1952). Congenital diaphragmatic hernia in siblings. British Medical fournal, 1, 1283-1284.

Potter, E. L. (1961). Pathology of the Fetus and Infant, 2nd ed., pp. 370-374. Year Book Medical Publishers, Chicago.

Powell, P. D. and Johnstone, J. M. (1962). Phenmetrazine and foetal abnormalities. British Medical fournal, 2, 1327.

Priester, W. A., Glass, A. G., and Waggoner, N. S. (1970). Congenital defects in domesticated animals: general considerations. American fournal of Veterinary Research, 31, 1871-1879.

Putschar, W. G. J. and Manion, W. C. (1956). Congenital absence of spleen and associated anomalies. American fournal of Clinical Pathology, 26, 429-470.

Reale, F. R. and Esterly, J. R. (1973). Pulmonary hypoplasia: a morphometric study of the lungs of infants with diaphragmatic hernia, anencephaly, and renal malformations. Pediatrics, 51, 91-96.

Rønn, G. and Andersen, S. (1971). Diaphragmatic hernias in Greenland. Scandinavian fournal of Thoracic and Cardiovascular Surgery, 5, 284-285.

Schwartz, D. L., Cohn, R. A., and Haller, J. A. (1974). Diaphragmatic hernia, three legs, two penises, and imperforate anus: a complete salvage problem in a newborn. fournal of Pediatric Surgery, 9, 525-529. 
Scott, J. M. and Paterson, L. (1966). Monozygous anencephalic triplets-a case report. Fournal of Obstetrics and Gynaecology of the British Commonwealth, 73, 147-151.

Selby, L. A., Hopps, H. C., and Edmonds, L. D. (1971). Comparative aspects of congenital malformations in man and swine. Fournal of the American Veterinary Medical Association, 159, 14851490.

Slater, B. C. S., Watson, G. I., and McDonald, J. C. (1964). Seasonal variation in congenital abnormalities. Preliminary report of a survey conducted by the research committee of council of the College of General Practitioners. British fournal of Preventive and Social Medicine, 18, 1-7.

Sokolowska-Pituchowa, J. and Kusionowicz, J. (1962). Congenital diaphragmatic defects. Folio biologica (Krakow), 10, 213-220.

Sommer, A. and Grosfeld, J. L. (1970). Trisomy E. and T-E fistula. Fournal of Medical Genetics, 7, 70-74.

Spencer, R. and Rogerson, M. M. (1951). Perforated peptic ulcer in a mongoloid infant associated with congenital diaphragmatic hernia. Archives of Disease in Childhood, 26, 566-569.

Symbas, P. N. and Ware, R. E. (1973). A syndrome of defects of the thoracoabdominal wall, diaphragm, pericardium, and heart. One-stage surgical repair and analysis of the syndrome. fournal of Thoracic and Cardiovascular Surgery, 65, 914-919.

Taylor, A. I. (1968). Autosomal trisomy syndromes: a detailed study of 27 cases of Edwards' syndrome and 27 cases of Patau's syndrome. Fournal of Medical Genetics, 5, 227-252.

ten Kate, L. P. and Anders, G. J. P. A. (1970). Unilateral agenesis of the diaphragm. Humangenetik, 8, 366-367.

Thorburn, M. J., Wright, E. S., Miller, C. G., and Smith-Read, E. H. M. (1970). Exomphalos-macroglossia-gigantism syndrome in Jamaican infants. American fournal of Diseases of Children, 119, 316-321.

Toyama, W. M. (1972). Combined congenital defects of the anterior abdominal wall, sternum, diaphragm, pericardium, and heart: a case report and review of the syndrome. Pediatrics, 50, 778-792.
Turpin, R., Petit, P., Chigot, P., Lafourcade, J., and de Barochez, Y. (1959). Hernie diaphragmatique congénitale de type embryonnaire (fente pleuro-péritonéale gauche). Coincidence chez deux cousins germains de cette malformation isolée. Annales de Pédiatrie, 35, 272-279.

Warkany, J. (1971). Congenital Malformations. Notes and Comments, p. 10; pp. 303-310; pp. 751-757. Year Book Medical Publishers, Chicago.

Warkany, J., Passarge, E., and Smith, L. B. (1966). Congenital malformations in autosomal trisomy syndromes. American fournal of Diseases of Children, 112,502-517.

Warkany, J. and Roth, C. B. (1948). Congenital malformations induced in rats by maternal vitamin A deficiency. Fournal of Nutrition, 35, 1-11.

Welch, R. G. and Cooke, R. T. (1962). Congenital diaphragmatic hernia. Lancet, 1, 975.

Willis, R. A. (1962). The Borderland of Embryology and Pathology, 2nd ed., p. 157. Butterworths, London.

W'ilson, J. G. and Gavan, J. A. (1967). Congenital malformations in nonhuman primates: spontaneous and experimentally induced. Anatomical Record, 158, 99-109.

Wilson, G. P., Newton, C. D., and Burt, J. K. (1971). A review of 116 diaphragmatic hernias in dogs and cats. Fournal of the American Veterinary Medical Association, 159, 1142-1145.

Wilson, J. G., Roth, C. B., and Warkany, J. (1953). An analysis of the syndrome of malformations induced by maternal vitamin A deficiency. Effects of restoration of vitamin $A$ at various times during gestation. American fournal of Anatomy, 92, 189-217.

Wolloch, Y., Grunebaum, M., Glanz, I., and Dintsman, M. (1974) Symptomatic retrosternal (Morgagni) hernia. American fournal of Surgery, 127, 601-605.

Zannetti, G. and Piccinini, V. (1974). L'ernia diaframmatica del cane. Folia veterinaria Latina, 4, 71-107.

Zolcinski, A., Heimrath, T., and Ujec, M. (1965). Chinina jako przyczyna wad rozwojowych plodu. Ginekologia Polska, 36, 935938. 